\title{
Modeling of an Air Conditioning System with Geothermal Heat Pump for a Residential Building
}

\author{
Silvia Cocchi, ${ }^{1}$ Sonia Castellucci, ${ }^{2}$ and Andrea Tucci ${ }^{1}$ \\ ${ }^{1}$ DAFNE, Università degli Studi della Tuscia, via San Camillo de Lellis, 01100 Viterbo, Italy \\ ${ }^{2}$ CIRDER, Università degli Studi della Tuscia, via San Camillo de Lellis, 01100 Viterbo, Italy
}

Correspondence should be addressed to Sonia Castellucci; sonia.castellucci@unitus.it

Received 14 December 2012; Accepted 10 January 2013

Academic Editor: Massimo Scalia

Copyright (C) 2013 Silvia Cocchi et al. This is an open access article distributed under the Creative Commons Attribution License, which permits unrestricted use, distribution, and reproduction in any medium, provided the original work is properly cited.

\begin{abstract}
The need to address climate change caused by greenhouse gas emissions attaches great importance to research aimed at using renewable energy. Geothermal energy is an interesting alternative concerning the production of energy for air conditioning of buildings (heating and cooling), through the use of geothermal heat pumps. In this work a model has been developed in order to simulate an air conditioning system with geothermal heat pump. A ground source heat pump (GSHP) uses the shallow ground as a source of heat, thus taking advantage of its seasonally moderate temperatures. GSHP must be coupled with geothermal exchangers. The model leads to design optimization of geothermal heat exchangers and to verify the operation of the geothermal plant.
\end{abstract}

\section{Introduction}

The increasing energy demands the fact that fossil fuels are finite resouces and the problem of pollutant emissions has allowed renewable energy sources (RES) to be considered and developed, including geothermal [1].

Geothermal energy is used in order to generate electricity or for direct uses, especially for heating [2]. Direct use of geothermal energy is the oldest and the most common utilization of this energy source.

There are many possibilities for these uses: geothermal heat pumps or ground source heat pumps (GSHPs), space heating, greenhouse and covered ground heating, aquaculture pond and raceway heating, agricultural crops drying, industrial process heat, snow melting and space cooling, bathing, and swimming [3].

The GSHP systems for heating and cooling are considered one of the most energy-efficient and cost-effective renewable energy technology [4]. Moreover these systems allow to reduce the greenhouse gases (GHGs) emissions [5].

Geothermal heat pumps systems use the subsoil (the interior of the earth) as a source and extract heat at low deep [6].

Heat pumps are devices that allow to transfer heat from a lower temperature system to a higher temperature system.
Geothermal heat pump or ground source heat pump (GSHP) is a heating and/or cooling system that pumps heat to or from the ground. The GSHP uses earth as a heat source (during winter time) or a heat sink (during summer time). This design takes advantage of the moderate temperatures in the ground to boost efficiency and reduce the operational costs of heating and cooling systems [7]. The major advantage of GSHPs derives from their better performance if compared with traditional system because they takes advantage of a more stable temperature of the heat source during the whole year, thus the coefficient of performance (COP) is increased, and the operational costs of heating and cooling are reduced [8].

The GSHPs systems can be classified as follows:

(i) open systems: if groundwater is used as heat transfer fluid,

(ii) closed systems: if there are some heat exchangers in the underground, and the groundwater is not the heat transfer fluid [9].

Among the closer systems there are many different configurations: horizontal, spiral, and vertical loop [10].

An air conditioning system with geothermal heat pumps consists of three parts [11]: 


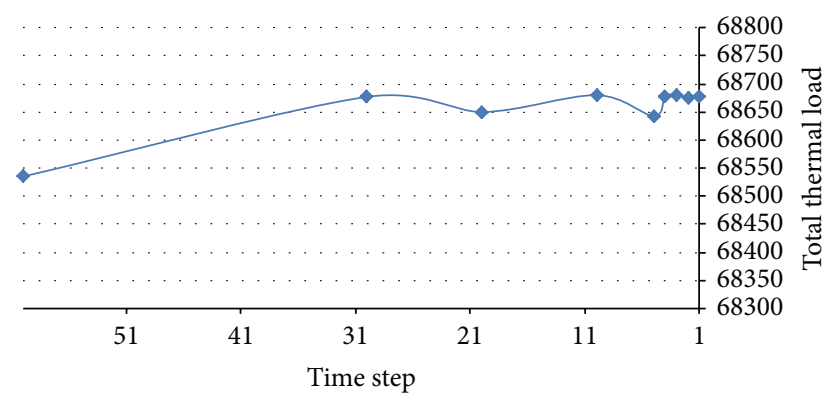

FIgURE 1: Thermal load as a function of time step.

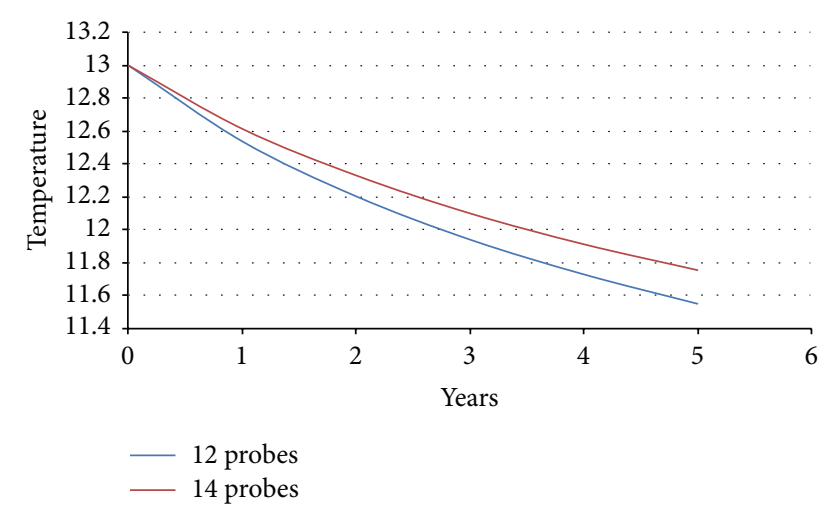

FIGURE 2: Ground temperature variations with exchanger numbers.

(i) geothermal heat exchangers,

(ii) heat pump,

(iii) heat distribution system (radiant floors are particularly suitable because they have the great advantage of working with lower temperature gradients if compared to conventional systems [12]).

The operating mechanism for heating is as follows:

(i) the fluid (antifreeze added water), flowing in geothermal heat exchangers, exchanges heat with the ground and comes back heated to surface;

(ii) fluid transmits its heat to the heat pump and back in the heat exchangers with lower temperature;

(iii) heat pump transmits its heat to the fluid flowing in radiant floors;

(iv) radiant floors heat the building.

GSHP must have a heat exchanger in contact with the ground or groundwater in order to extract or dissipate heat. Several major design options are available for these, which are classified according to layout and fluid: direct exchange systems circulate refrigerant underground, closed loop systems use a mixture of antifreeze and water, and open loop systems use natural groundwater. Direct exchange geothermal heat pump is the oldest type of geothermal heat pump technology.

In this work a GSHP system with vertical heat exchangers has been studied.

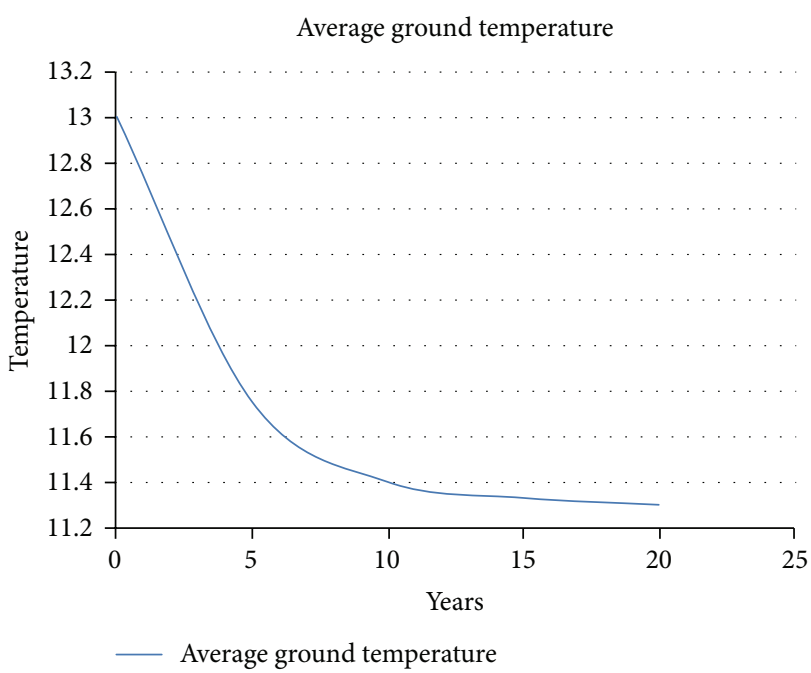

FIgURE 3: Average ground temperature for 14 exchangers in 20 years.

The growth of GSHPs technology was slower than other RES or conventional technologies due to many factors: nonstandardized system designs, significant capital costs if compared with other systems, and limited individuals knowledgeable in the installation of GSHP systems. Nevertheless these problems have been resolved on an ongoing basis, and the acceptance of the GSHP technology is increasing [1].

GSHP systems COP is higher than COP of other heat pump systems: it usually varies from 3 to 6 , depending on the earth connection setups, system sized earth characteristics, installation depths, and climate of the area. Instead, for example, for an air source heat pump system the COP range is from 2,3 to 3,5 [1].

GSHP systems have higher initial costs than conventional ones because of the costs of the heat pump unit and the connection with the ground, specially drilling, but the operating costs are lower than conventional systems because of their high efficiency. Therefore the economic feasibility of GSHP systems depends on location, due to the price of electricity, natural gas, and other heating fuel. If these are not expensive, GSHP system may not be the cheapest option. On the contrary when there are low electricity costs, the GSHP systems are economically advantageous [1].

In particular, for example, if electricity is produced by a photovoltaic system the operating costs and the GHG emissions become remarkably low.

Therefore in order to increase the efficiency of the GSHP system and to reduce the costs, the optimal sizing of the plant is needful. The TRNSYS 17 software can be used for the system simulation in order to refine the sizing.

\section{Methods}

2.1. Presizing. The studied building is part of a building complex and consists of 14 apartments located over 4 floors.

The building was planned to include a central heating system, for heating and domestic hot water, that uses one heat pump and vertical geothermal heat exchangers. During 


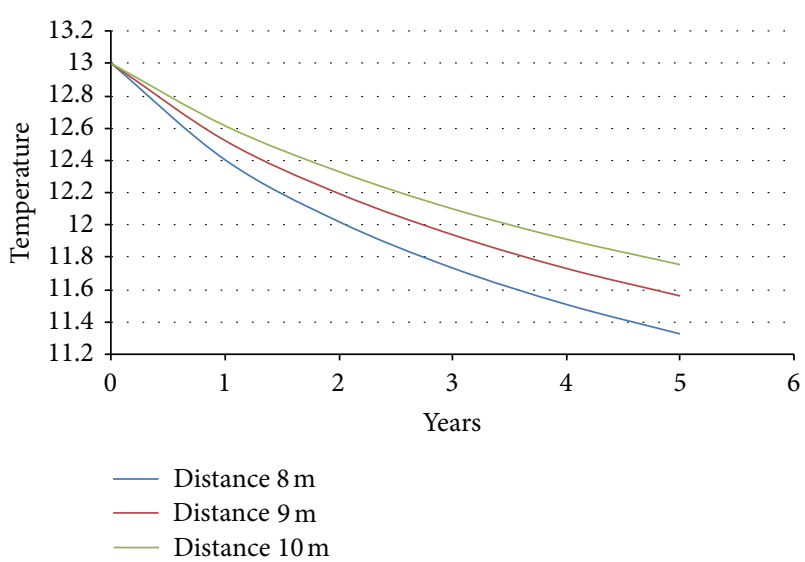

FIGURE 4: Average ground temperature varying number of exchangers.

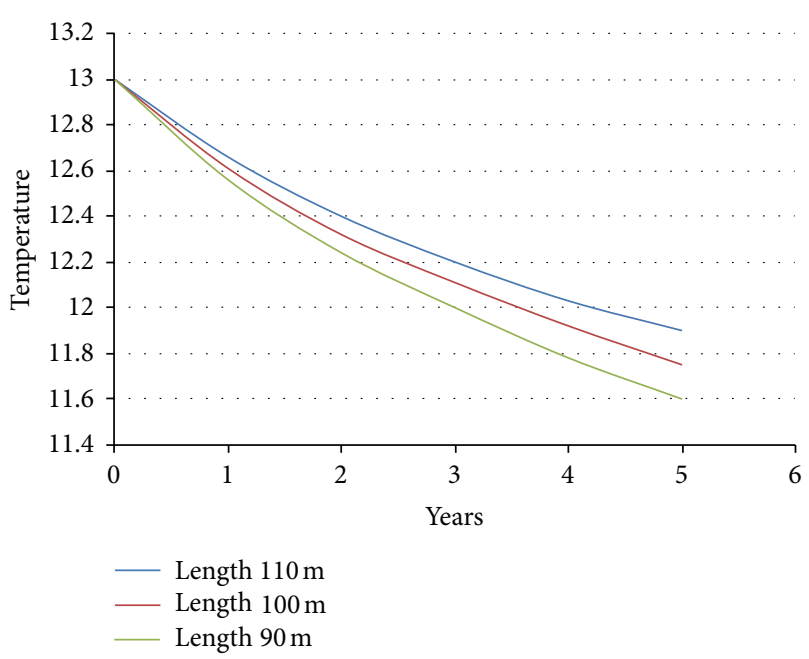

FIgURE 5: Average ground temperature varying exchangers length.

TABLE 1: Data for calculation of thermal load.

\begin{tabular}{lcc}
\hline Building data & \\
Thermal zone & $\mathrm{D}$ \\
Number of heating days & 167 \\
Daily hours of heating & 12 \\
Heated surface (gross) & $\mathrm{m}^{2}$ & 3510,61 \\
Outer surface that bounds the volume & $\mathrm{m}^{2}$ & 2101,73 \\
Usable area & $\mathrm{m}^{2}$ & 930 \\
Climatic data project & & \\
Value of internal project temperature & ${ }^{\circ} \mathrm{C}$ & 20 \\
\hline
\end{tabular}

summer time, the system works in natural cooling operative mode.

The thermal load of the building is $43,2 \mathrm{~kW}$ for heating (Table 1).

We choose one geothermal heat pump with a power of $47,2 \mathrm{~kW}$, whose fluid consists of water and ethylene glycol $(25 \%)$, with freezing temperature of $-13^{\circ} \mathrm{C}$.

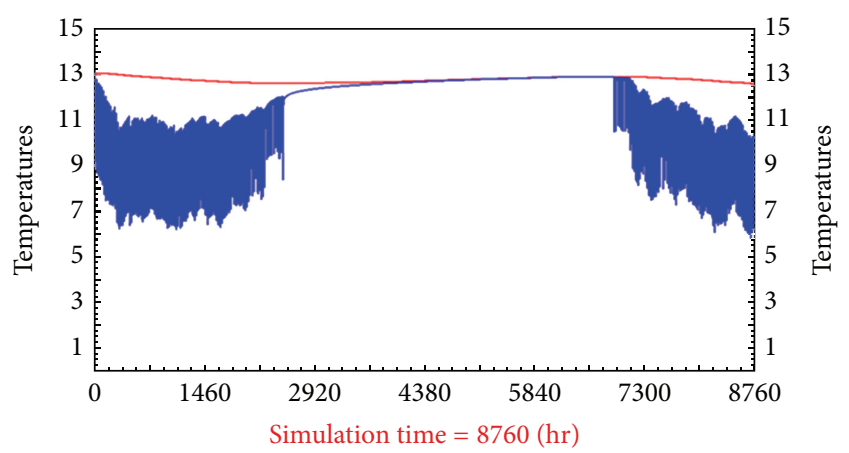

FIGURE 6: Fluid temperature in output from exchangers during the first year.

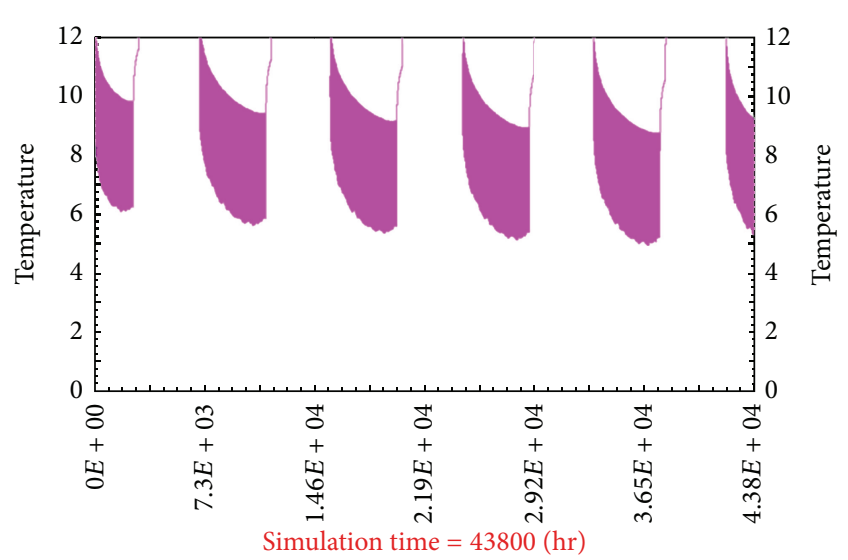

FIGURE 7: Fluid temperature in output from exchangers during 5 years.

TABLE 2: Features of vertical heat exchangers.

\begin{tabular}{lc}
\hline Features of vertical exchangers & \\
Number & 12 \\
Length & $100 \mathrm{~m}$ \\
Distance & $8 \mathrm{~m}$ \\
Type & single U \\
External diameter U & $32 \mathrm{~mm}$ \\
Internal diameter U & $29 \mathrm{~mm}$ \\
Bore diameter & $12 \mathrm{~cm}$ \\
Distance by centers of U & $5 \mathrm{~cm}$ \\
\hline
\end{tabular}

Geothermal heat exchangers have been presized according to the procedure described in VDI4640 German law [9]. The procedure of VDI4640 is strictly applied for small sized systems $(<30 \mathrm{~kW})$, but we used this procedure for an approximate sizing only. Then the final size has been obtained by the approximate one, by simulation with software TRNSYS 17.

The presizing procedure of VDI4640 is the following [13]:

(1) calculation of heating load $P_{t}(=43,2 \mathrm{~kW})$;

(2) definition of temperature of radiant floor $\left(=35^{\circ} \mathrm{C}\right)$; 


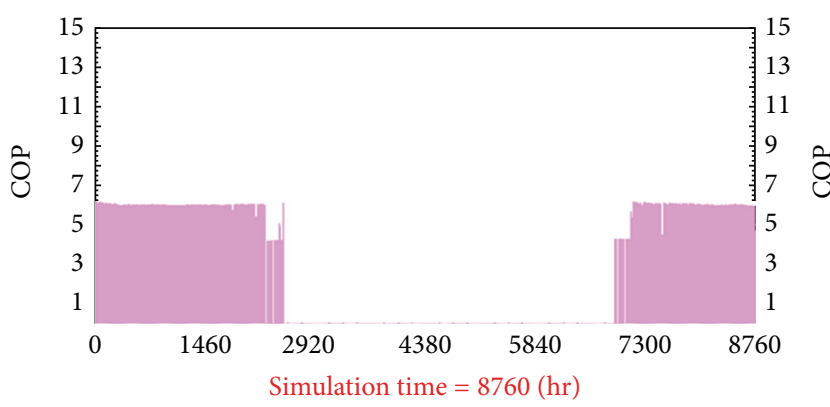

FIgURE 8: COP of heat pump in the first year (during winter time).

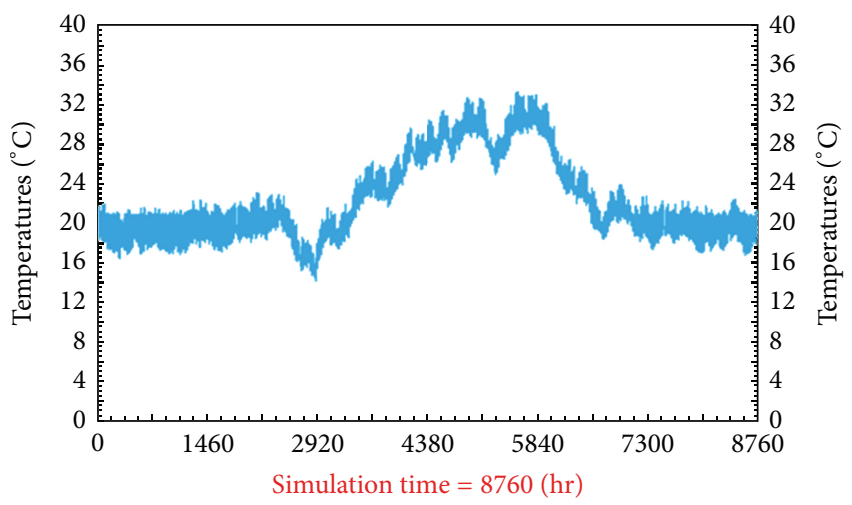

FIgURE 9: Air temperature in the apartment.

(3) choice of heat pump and definition of the COP (coefficient of performance) with the operating condition $\mathrm{B} 0 / \mathrm{W} 35, \mathrm{COP}=4,33$;

(4) calculation of the power exchanged with the ground $P_{\mathrm{ev}}\left[=(\mathrm{COP}-1) P_{t} / \mathrm{COP}=33,22 \mathrm{~kW}\right]$;

(5) extraction from VDI4640 of the specific power extraction $P_{\text {ter }}(=30 \mathrm{~W} / \mathrm{m})$;

(6) calculation of total length of vertical geothermal heat exchangers $L\left(=P_{\text {ev }} / P_{\text {ter }}=1107 \mathrm{~m}\right)$;

(7) oversized (15\%) $L=1273 \mathrm{~m}$;

(8) assumption of 12 vertical heat exchangers (each one $100 \mathrm{~m}$ long) (Table 2).

2.2. Simulation. The software TRNSYS 17 has been used in order to simulate the operations system.

TRNSYS is a complete and extensible simulation environment for the transient simulation of systems, including multizone buildings.

TRNSYS consists of a suite of programs: the TRNSYS Simulation Studio, the Simulation Engine (TRNDll.dll) with its executable (TRNExe.exe), the Building input data visual interface (TRNBuild.exe), and the Editor used to create stand-alone redistributable programs, known as TRNSED applications (TRNEdit.exe) [14].

The main visual interface is the TRNSYS Simulation Studio. Here, we can create projects by drag-and-dropping components to the workspace, connecting them together and

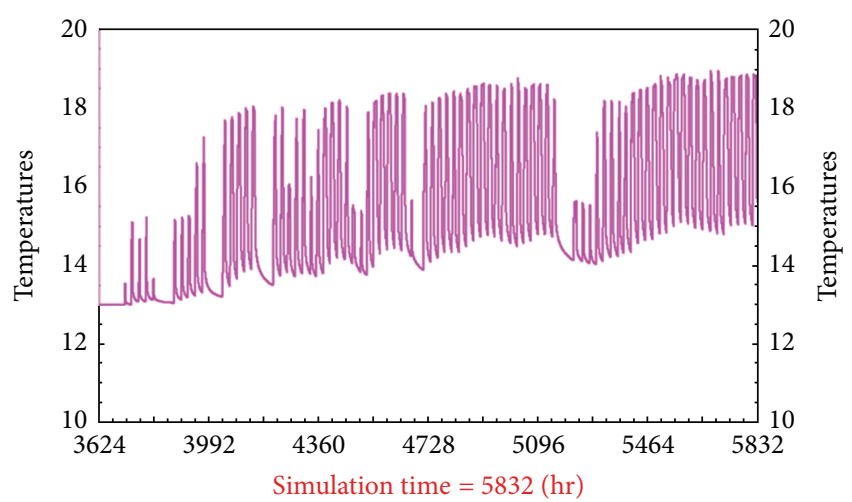

FIGURE 10: Fluid temperature in input in radiant floor in summer (natural cooling).

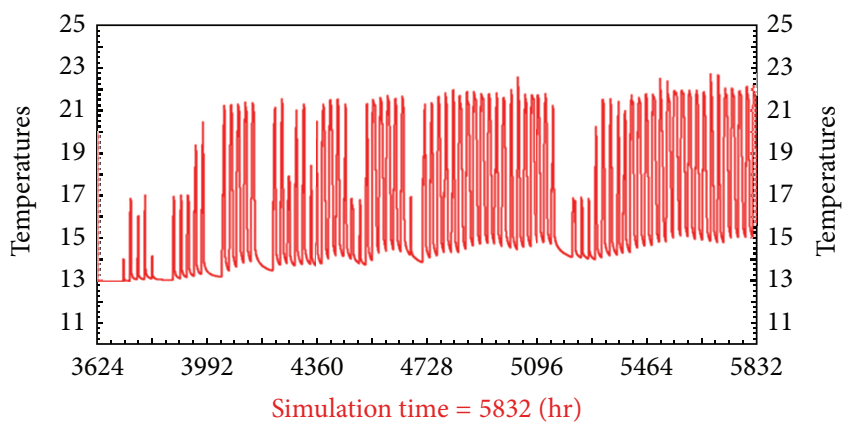

FIGURE 11: Fluid temperature in output from radiant floor in summer (natural cooling).

setting the global simulation parameters. When you run a simulation, the Studio also creates a TRNSYS input file (a text file, that contains all simulation information but no graphical information).

The Simulation Studio also includes an output manager, by which you control which variables are integrated, printed, and/or plotted, and a log/error manager that allows you to study in detail what happened during the simulation [15].

The system has been represented in TRNSYS Simulation Studio and the Building has been created in TRNBuild.

The Building has been modeled in TRNBuild by dividing it into 16 thermal zones (14 apartments, 1 zone of stairs, and 1 garage) [16].

The simulation with TRNSYS 17 allows the calculation and displays one or more variables on interval of time. Most of variables are studied within annual simulation, but average ground temperature is studied in five-year simulation.

We studied the following variables:

(1) thermal loads;

(2) air temperature in thermal zones;

(3) fluid temperature in input and output from radiant floors;

(4) fluid temperature in input and output from geothermal heat exchanger;

(5) average ground temperature; 
(6) COP of heat pump;

(7) optimal time step for simulations.

Optimal time step has been studied observing building thermal loads varying with time steps.

\section{Results}

The results of the simulation are represented in Table 3 and in Figure 1.

The optimal time step for simulation is 1 minute.

The study of average ground temperature is very important because this variable must not change more than $2^{\circ} \mathrm{C}$ over long period. Simulations are carried out for more conditions $(12,13$, and 14 exchangers; distance between exchangers of 8 , 9 , and $10 \mathrm{~m}$; arrangement of exchangers in series and parallel; length of exchanger of 90, 100, and $110 \mathrm{~m}$ ).

We have chosen the following as target for the average ground temperature:

(1) ensure no overexploitation of the ground;

(2) achieve a new balance for the ground average temperature.

Changes in ground temperature varying with number of exchangers are shown in Figure 2.

The average ground temperature change after 20 years is shown in Figure 3 , and it is equal to $1,7^{\circ} \mathrm{C}$, below the threshold of $2^{\circ} \mathrm{C}$, necessary not to have an overexploitation.

Changes in average ground temperature as a function of distance between exchanger are shown in Figure 4.

Changes in average ground temperature varying with exchangers length are shown in Figure 5.

We obtained that the configuration which gives the best performance has the following characteristics: 14 vertical exchangers in series with distance of $10 \mathrm{~m}$ and length of $100 \mathrm{~m}$ (Table 4).

The temperature of fluid in output from exchangers is represented in Figure 6.

It can be seen in Figure 6 that during the first year the minimum temperature of the fluid in output from the exchangers is $6^{\circ} \mathrm{C}$. In Figure 7 we can see that the same temperature at five years is $5^{\circ} \mathrm{C}$.

The temperature of fluid in input in the heat pump is in the allowable range $\left(-5,+25^{\circ} \mathrm{C}\right)$.

The COP of the heat pump is represented in Figure 8. Note that the performance is good because COP is always more than 4.

Moreover, it resulted that the minimum temperature of the fluid in output from the heat pump is $1,5^{\circ} \mathrm{C}$. The heating due to the ground is $4,5^{\circ} \mathrm{C}$.

Air temperature in the apartments (represented in Figure 9) ensure comfort conditions.

The fluid temperature in input in the radiant floors resulted $19^{\circ} \mathrm{C}$ at the end of the summer, while fluid temperature in output at the end of the summer was $22^{\circ} \mathrm{C}$ as shown in Figures 10 and 11.
TABLE 3: Thermal load varying time step simulation.

\begin{tabular}{lc}
\hline Time-step & Total thermal load [kWh] \\
\hline 1 hour & 68535,845218584532 \\
30 minutes & 68677,478548530451 \\
20 minutes & 68469,790308356302 \\
10 minutes & 65833,167347961783 \\
5 minutes & 68533,186713158425 \\
4 minutes & 68678,316559261531 \\
3 minutes & 68680,138881754820 \\
2 minutes & 68676,275556369017 \\
1 minute & 68677,942675267512 \\
\hline
\end{tabular}

TABLE 4: Configuration of exchangers that gives the best performance.

\begin{tabular}{lc}
\hline Number of vertical exchangers & 14 \\
Distance & $10 \mathrm{~m}$ \\
Length & $100 \mathrm{~m}$ \\
Configuration & 14 exchangers in series \\
\hline
\end{tabular}

\section{Conclusion}

In order to refine the sizing of the system, the TRNSYS 17 software is used.

The simulation of the system over a period of 5 years shows the best configuration for the exchangers: 14 vertical heat exchangers in series with distance of $10 \mathrm{~m}$ and length of $100 \mathrm{~m}$.

The results show that the system works properly, because

(1) the temperature in the apartments ensures comfort conditions;

(2) the ground is not subject to overexploiting;

(3) high heat pump efficiency.

Simulation with software TRNSYS allows to refine the sizing of the system and accordingly to reduce the initial costs for the ground connection-in particular for drilling and probes that are about the $35 \%$ of the total costs-and the operating costs.

\section{Conflict of Interests}

The authors certify that there is no conflict of interests with any financial organization regarding the material discussed in the paper.

\section{References}

[1] S. J. Self, B. V. Reddy, and M. A. Rosen, "Geothermal heat pump systems: status review and comparison with other heating options," Applied Energy, vol. 101, pp. 341-348, 2013.

[2] E. Barbier, "Geothermal energy technology and current status: an overview," Renewable and Sustainable Energy Reviews, vol. 6, no. 1-2, pp. 3-65, 2002.

[3] M. Carlini and S. Castellucci, "Efficient energy supply from ground coupled heat transfer source," in Proceedings of the International Conference on Computational Science and Applications 
(ICCSA '10), vol. 6017 of Lecture Notes in Computer Science, part 2, pp. 177-190, Springer, Fukuoka, Japan, 2010.

[4] J. W. Lund, D. H. Freeston, and T. L. Boyd, "Direct application of geothermal energy: 2005 worldwide review," Geothermics, vol. 34, no. 6, pp. 691-727, 2005.

[5] A. M. Omer, "Ground-source heat pumps systems and applications," Renewable and Sustainable Energy Reviews, vol. 12, no. 2, pp. 344-371, 2008.

[6] P. Bayer, D. Saner, S. Balay, L. Rybach, and P. Blum, "Greenhouse gas emission savings of ground source heat pump systems in Europe: a review," Renewable and Sustainable Energy Reviews, vol. 16, no. 2, pp. 1256-1267, 2012.

[7] M. Carlini and S. Castellucci, "Modelling tha vertical heat exchanger in thermal basin," in Proceedings of the International Conference on Computational Science and Applications (ICCSA '11), vol. 6785 of Lecture Notes in Computer Science, part 4, pp. 277-286, Springer, Santander, Spain, 2011.

[8] M. Carlini and S. Castellucci, "Modelling and simulation for energy production parametric dependence in greenhouses," Mathematical Problems in Engineering, vol. 2010, Article ID 590943, 28 pages, 2010.

[9] Y. Bi, X. Wang, Y. Liu, H. Zhang, and L. Chen, "Comprehensive exergy analysis of a ground-source heat pump system for both building heating and cooling modes," Applied Energy, vol. 86, no. 12, pp. 2560-2565, 2009.

[10] J. Mazo, M. Delgado, J. M. Marin, and B. Zalba, "Modeling a radiant floor system with Phase Change Material (PCM) integrated into a building simlation tool: analysis of a case study of a floor heating system coupled to a heat pump," Energy and Buildings, vol. 47, pp. 458-466, 2012.

[11] C. Cattani, S. Chen, and G. Aldashev, "Information and modeling in complexity," Mathematical Problems in Engineering, vol. 2012, Article ID 868413, 4 pages, 2012.

[12] S. Y. Chen, H. Tong, and C. Cattani, "Markov models for image labeling," Mathematical Problems in Engineering, vol. 2012, Article ID 814356, 18 pages, 2012.

[13] VDI Technical Division Energy Conversion and Application, Thermal Use of the Underground-Ground Source Heat Pump Systems, 2001.

[14] M. Carlini, T. Honorati, and S. Castellucci, "Photovoltaic greenhouses:comparison of optical and thermal behaviour for energy savings," Mathematical Problems in Engineering, vol. 2012, Article ID 743764, 10 pages, 2012.

[15] M. Carlini, S. Castellucci, M. Guerrieri, and T. Honorati, "Stability and control for energy production parametric dependence," Mathematical Problems in Engineering, vol. 2010, Article ID 842380, 21 pages, 2010.

[16] Solar Energy Laboratory, University of Wisconsin, TRNSYS 17 Documentation. 


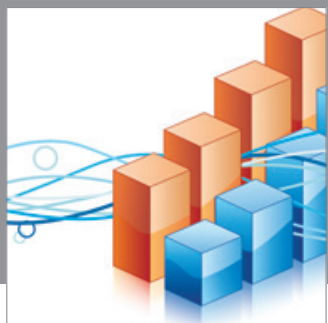

Advances in

Operations Research

mansans

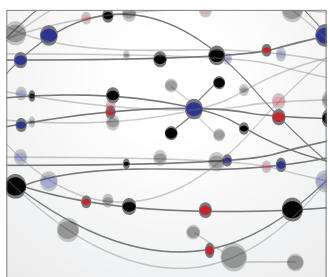

The Scientific World Journal
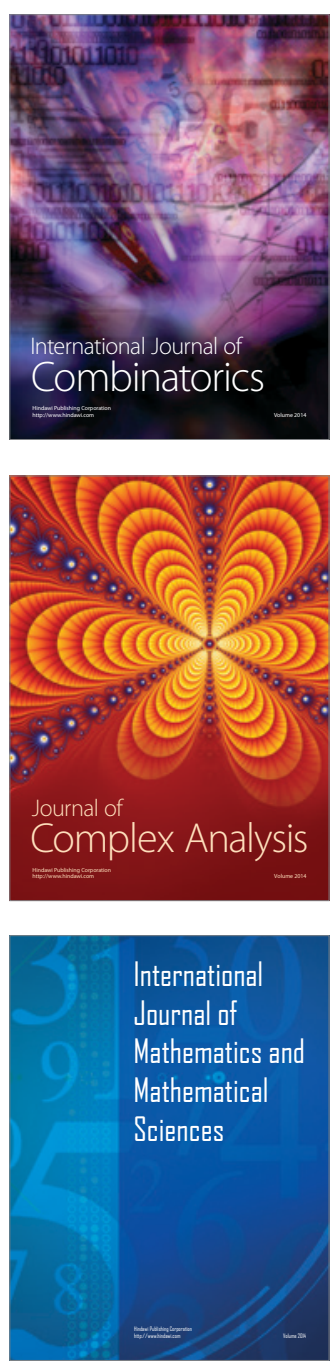
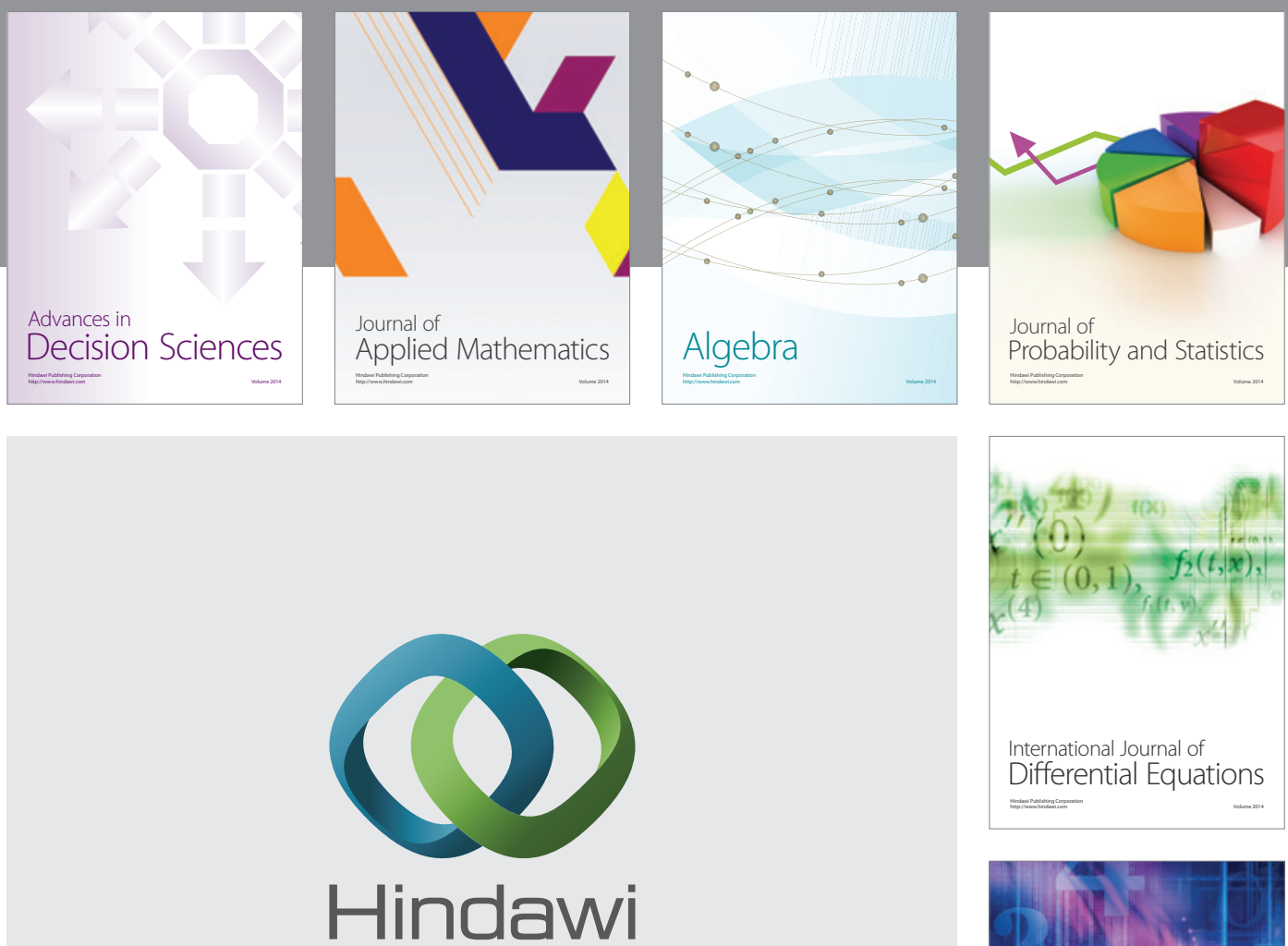

Submit your manuscripts at http://www.hindawi.com
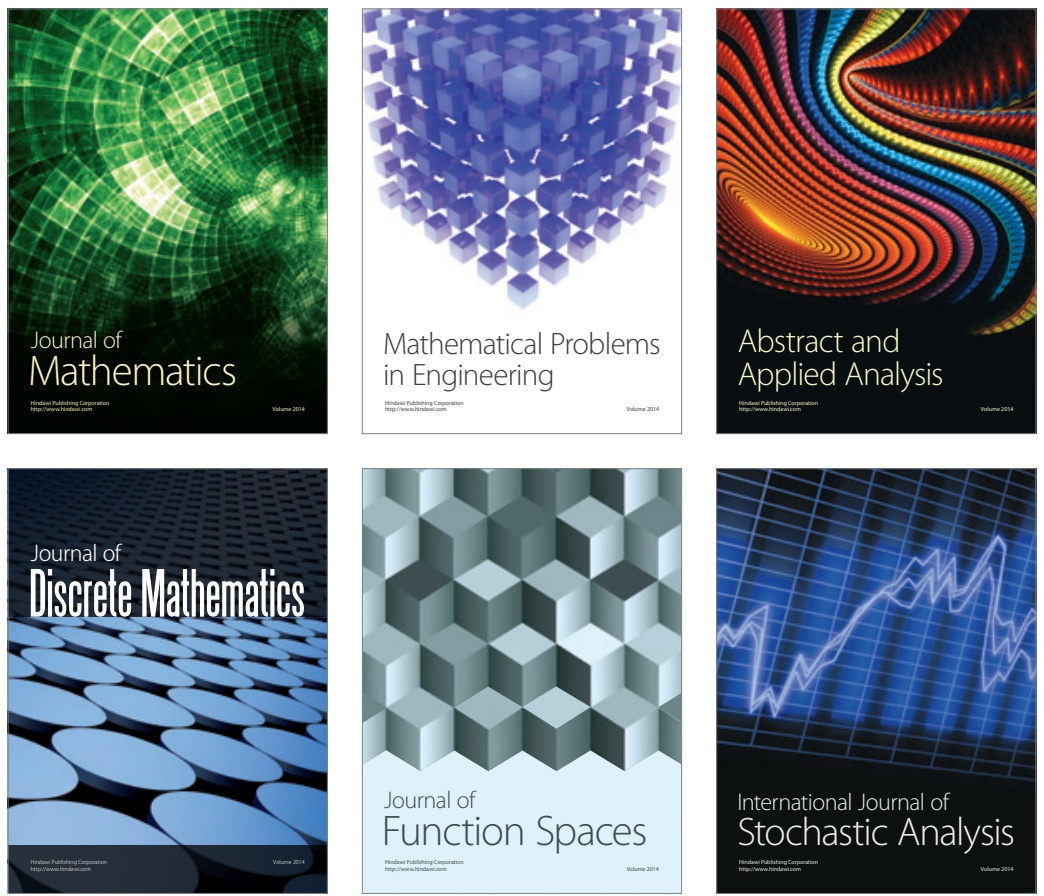

Journal of

Function Spaces

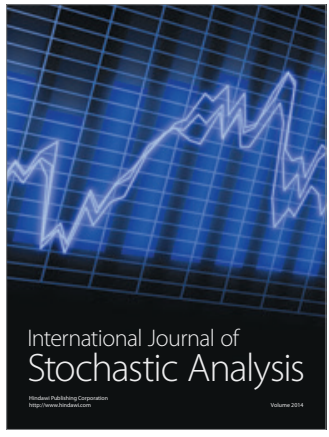

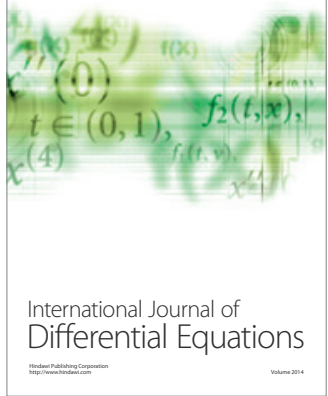
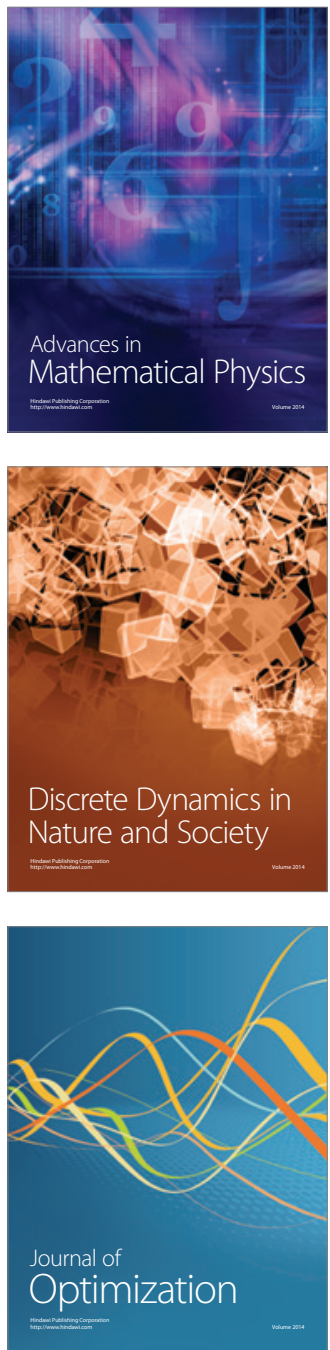